\title{
Anterior cervical corpectomy and fusion in a 7-year-old boy: a case report
}

\author{
Mohamad Saekhu, Samsul Ashari, David Tandian, Setyo Widi Nugroho
}

pISSN: 0853-1773 • elSSN: 2252-8083 https://doi.org/10.13181/mji.v28i2.2673 Med J Indones. 2019;28:183-7

Received: February 27, 2018

Accepted: January 19, 2019

Authors' affiliations:

Department of Neurosurgery, Faculty of Medicine, Universitas Indonesia, Cipto Mangunkusumo Hospital, Jakarta, Indonesia

\section{Corresponding author:}

Mohamad Saekhu Department of Neurosurgery, Faculty of Medicine, Universitas Indonesia, Cipto Mangunkusumo Hospital, Jalan Diponegoro Nomor 71, Kenari, Senen, Central Jakarta 10310, DKI Jakarta,

Indonesia

Tel/Fax: +62-21-3145554

E-mail: saekhu2010@hotmail.com

\begin{abstract}
Bicycle mishap, a common and ordinary event occurring in children, can have devastating consequences associated with cervical spine injury. Furthermore, either diagnosis or surgical management of cervical spine injury in children is a challenging issue. This research report a challenging case of an anterior cervical corpectomy and fusion with plating in a 7-year-old boy due to cervical spine instability with spinal cord compression after a bicycle mishap. After 20 months of the primary surgery, the titanium-based cervical plate was removed by a second surgery to allow the growth of the cervical spine.
\end{abstract}

KEYWORDS anterior cervical corpectomy, case report
Anterior cervical corpectomy and fusion (ACCF) is an effective and safe treatment option for adults for decompression of cervical cord compression ${ }^{1}$ as well as for traumatic cervical spine (C-spine) instability. ${ }^{2}$ Two implants are required for the ACCF procedure. The first implant is a graft used to reconstruct the vertebral body after corpectomy of the vertebral corpus/body, which can be titanium-based (allograft) or an iliac crest bone graft (autograft). The second implant is a titanium-based cervical plate used to reduce the risk of graft extrusion and enhance the fusion rate. ${ }^{3}$ Compared with adults, ACCF in children aged $<10$ years is more challenging because of the absence of dedicated implants that accommodate the size and the growth potential of the pediatric C-spine, ${ }^{4}$ as well as the rarity of the case resulting in a scarcity of related literature. ${ }^{3}$ The youngest age of any patient who underwent ACCF for C-spine trauma was 16 years, ${ }^{1,2}$ where the size of the C-spine was relatively comparable to that of adults.
Moreover, the insertion of titanium-based implants (instrumentation) in children was associated with a higher risk of complications. 5 Among the complications is spinal deformity that is caused due to continued growth of the child's immature spine in the fixed levels. ${ }^{6,7}$ This study reports another case of ACCF to the body of existing literature that was performed by titanium-based cervical plating in a 7-year-old boy. The plate was removed in a second operation 20 months after the first operation. This objective was to report the clinical and radiological outcome at 1-year follow-up after removing the plate.

\section{Case report}

A 7-year-old boy with a history of bicycle mishaps with his neck bent 6 months ago, followed by neck pain that was provoked by movement of the neck and/or the head. After 1 week, the family took the boy to a district-level hospital where he underwent 
physiotherapy. After 4 months, he complained of weakness in both sides of the arms and legs and numbness from the lower neck to the arms, and he was able to walk but unsteadily. His parents took him to a national hospital (Cipto Mangunkusumo Hospital) where he underwent C-spine X-ray evaluation and magnetic resonance imaging (MRI). After 1 month of being hospitalized under conservative therapy (nonsurgical) but without recovery and/or reduction of the neck pain, his parents brought him to Department of Neurosurgery, Faculty of Medicine, Universitas Indonesia.

Neurological examination revealed devastating neck pain during every neck motion or movement, i.e., the Wong-Baker FACES pain rating scale was $8-10,{ }^{8}$ tetraparesis with a motor strength of 4 (motor strength ranges from 0 to 5 ; the normal motor strength is 5), and the Hoffman-Tromner sign was positive that indicated an upper motor neuron lesion (the affected spinal cord was at the $\mathrm{C}-4$ level or above). C-spine X-rays demonstrated a reverse lordosis and a retrolisthesis of C-4 (Figure 1a). MRI examination revealed a slight compression of the thecal sac from C -3 to $\mathrm{C}-5$ from the ventral side of the spinal cord (Figure 1b).

The authors decided to decompress the spinal canal and stabilize the C-spine. The patient was placed in the supine position on the operating table with his head and neck in neutral position with slight extension. General anesthesia was maintained, and prophylactic antibiotics were used. A right-sided approach to the
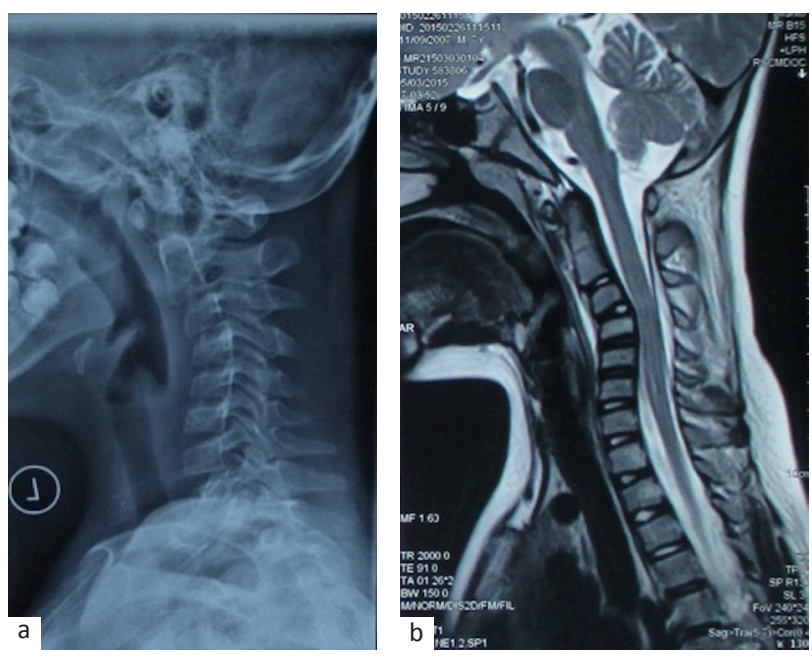

Figure 1. Imaging pre-surgery. (a) X-ray shows reverse lordosis of the C-spine with C-4 in the center; (b) Sagittal T2 MRI shows compression of the spinal cord and enlargement of the central canal below the center of the reverse lordosis. $\mathrm{MRI}=$ magnetic resonance imaging spine was made, with a horizontal skin incision as high as the thyroid cartilage $1 \mathrm{~cm}$ from the midline in the left side to $3 \mathrm{~cm}$ from the midline in the right side. The skin was freed from the platysma to obtain the expected operative target area, i.e., the region from the upper part of the vertebral body of $\mathrm{C}-3$ to the lower part of the vertebral body of $\mathrm{C}-5$ was exposed. The platysma was incised vertically in the medial border of the sternocleidomastoid muscle. The operative target area was achieved by blunt dissection between the sternocleidomastoid muscle and the carotid sheath with the trachea and the esophagus. The longus colli musculature and the suspected intervertebral disc (IVD) between C-4 and C -5 were identified. The IVD between $\mathrm{C}-4$ and $\mathrm{C}-5$ was confirmed by intraoperative radiography, followed by dissection of the longus colli musculature to expose the vertebral body $2 \mathrm{~cm}$ wide. The operative target area was maintained by a Caspar cervical retractor. The anterior longitudinal ligament was incised, and all discectomy procedures on the IVD between $\mathrm{C}-3$ and $\mathrm{C}-4$, and the IVD between $\mathrm{C}-4$ and $\mathrm{C}-5$ were carried out using curettage and Caspar rongeur under an image intensifier (surgical microscope). Among the special tricks in performing a discectomy is avoiding or being careful in using a high-speed drill (HSD) as it can easily slip and injure the major blood vessels and/or the esophagus or the trachea. Another skill is ensuring that all IVD tissues are removed to allow a better chance of fusion. Next, corpectomy was performed using a bone rongeur knabel tang and HSD under a surgical microscope. The uncinate processes were identified and used as reference points for establishing the width of the required corpectomy. Posterior cortical bone and posterior longitudinal ligament were removed microsurgically with the aid of an operating microscope. Decompression was considered to be successful when the surgeon could directly visualize a protruding pulsating dural sac. In this case, there was an epidural hematoma. The hematoma until the dural sac and its pulses could be visualized (Figure 2a). Iliac bone graft (IBG) was used as a fusion material, which was taken from the right ilium bone according to the required size and inserted into the space created by corpectomy and discectomy with the help of manual stretching between $\mathrm{C}-3$ and C-5 (Figure 2b). Then, a titanium-based cervical plate was inserted into the anterior aspect of the vertebral body of C-3 and C-5 (Figure 2c). Before completing the surgeries, an intraoperative radiography was

mji.ui.ac.id 

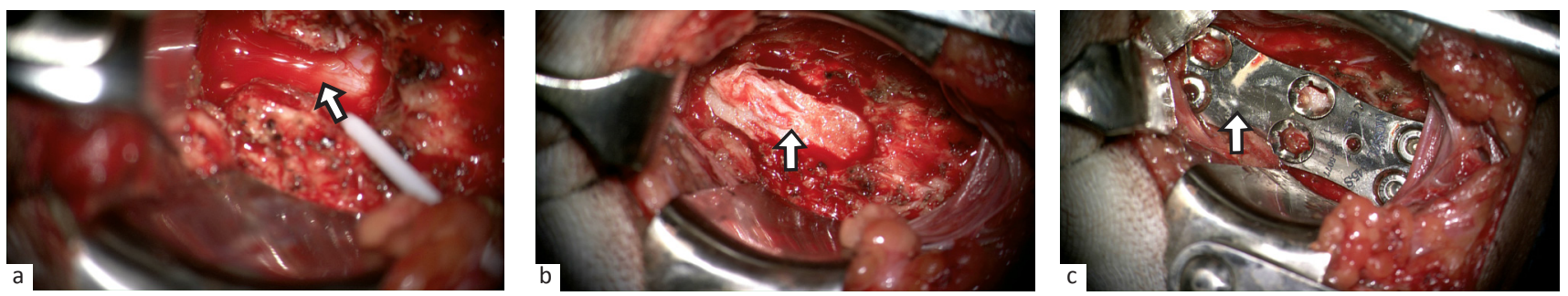

Figure 2. Intraoperative figures. (a) Duramater spinalis (white arrow) was exposed after corpectomy and hematoma evacuation; (b) Reconstruction of the vertebrae by installing the autograft of iliac bone (white arrow); (c) Titanium-based plate (white arrow) was inserted

performed to ensure that the plate was in a good position. A soft cervical collar was immediately worn that was maintained for up to 3 months postoperatively. One day after the surgery, the neck pain decreased (the Wong-Baker FACES pain rating scale was 2), and the motor strength increased subjectively.

The patient was discharged from the hospital on the seventh day, and he was followed up at the outpatient clinic at 1 week, 1 month, 3 months after discharge from the hospital, and then at every 6 months. Follow-up investigations consisted of clinical and radiological tests (Table 1). The motor strength recovered completely at 3 months after surgery. Radiological investigation via plain films was done on the following day after surgery to ensure proper positioning of the bone graft and the plate-screw system. Plain films and MRI findings were evaluated at 6 months after the first surgery (Figure 3, a and b). Computed tomography (CT) was performed 20 months after the first surgery to confirm the radiological fusion as well as the adequate decompression (Figure $3 \mathrm{C}$ ). The authors decided to perform a second surgery to remove the cervical plate in the next week. After 6 months of removing the plate, the radiological finding was found to be satisfactory (Figure 4).

\section{DISCUSSION}

Bicycle mishaps occur commonly in children of elementary school age and therefore considered as an ordinary event by the community. However, it has been reported that C-spine injury related to bicycle mishaps accounted for $5 \%$ of traumatic C-spine injuries, and a traumatic C-spine injury can have devastating consequences. ${ }^{9}$ The mortality rate among children without neurologic deficits has been estimated at $15 \%, 9$ and the unfavorable outcome (Frankel grade E) accounted for $45 \% .^{10}$ Proper diagnosis and therapy is
Table 1. Outcomes of clinical and radiological tests

\begin{tabular}{|c|c|c|}
\hline \multirow[b]{2}{*}{ Indicators } & \multicolumn{2}{|c|}{ Follow-up periods } \\
\hline & Pre-surgery & $\begin{array}{c}2 \text { years } \\
\text { after surgery }\end{array}$ \\
\hline $\begin{array}{l}\text { Wong-Baker FACES pain rating } \\
\text { scale }\end{array}$ & 8 & 0 \\
\hline JOA & 12 & 17 \\
\hline NDI & 18 & 0 \\
\hline 10-m walking time (sec) & NA & 10 \\
\hline \multicolumn{3}{|l|}{ Length of hospital stay (days) } \\
\hline $1^{\text {st }}$ surgery & \multicolumn{2}{|c|}{7} \\
\hline $2^{\text {nd }}$ surgery & \multicolumn{2}{|r|}{3} \\
\hline \multicolumn{3}{|l|}{ Donor site morbidity } \\
\hline Donor site pain & \multicolumn{2}{|c|}{ Negative } \\
\hline Surgical site infection & \multicolumn{2}{|c|}{ Negative } \\
\hline \multicolumn{3}{|l|}{ Cervical curvature (Cobb's angle) } \\
\hline & Pre-surgery & $\begin{array}{l}\text { Six months } \\
\text { after } \\
\text { removing the } \\
\text { plate }\end{array}$ \\
\hline X-rays: $\mathrm{C}-2$ to $\mathrm{C}-5$ & $-26^{0}$ & $-18^{0}$ \\
\hline $\mathrm{X}$-rays: $\mathrm{C}-2$ to $\mathrm{C}-7$ & $-19^{0}$ & $+4^{0}$ \\
\hline
\end{tabular}

JOA=Japanese Orthopedic Association; NDI=Neck Disability Index; NA=not applicable

extremely important for managing patients with a suspicion of C-spine injury. Evaluation of the C-spine by clinical or radiological methods has been a subject of debate. Earlier, the majority of C-spine radiographs for clearing the C-spine in every blunt trauma patient were found to be normal. On the other hand, X-rays have the risk of increasing the exposure to ionizing radiation. The National Emergency X-Radiography Utilization Study (NEXUS) recommend C-spine imaging in patients who have a history of injury along with clinically apparent painful distracting injury. The sensitivity of the NEXUS recommendation was found to reach $100 \%{ }^{11}$ This case confirmed the sensitivity of the NEXUS recommendation and also confirmed 

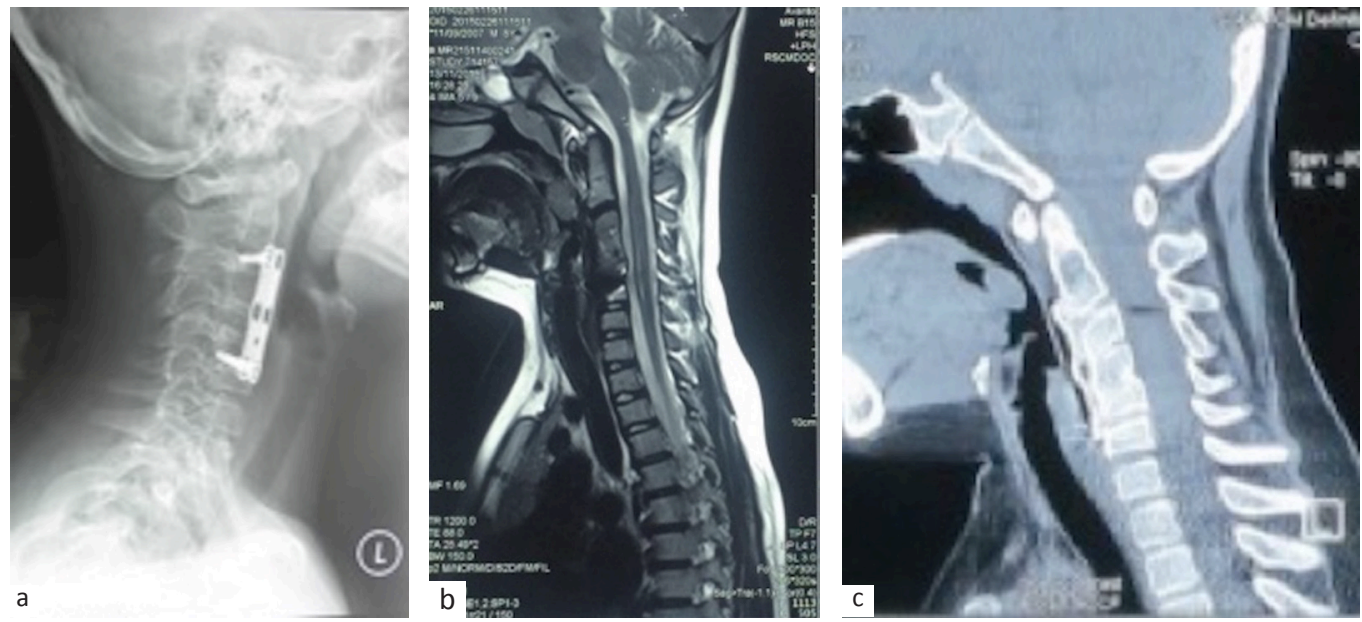

Figure 3. Imaging post-surgery. (a) X-ray after 6 months of the first surgery: the plate was in a good position; (b) Sagittal T2 MRI 7 months after the first surgery shows no longer spinal decompression; (c) CT scan sagittal view 20 months after the first surgery showed fusion

that the pain that was primarily worsening and/or triggered by movement is a significant sign of spinal instability after spinal injury. ${ }^{12}$ In the clinical setting, there is a triad of symptoms of cervical spine injury, i.e., local/neck pain, limitation of the neck movement, and muscle spasm. ${ }^{13} \mathrm{~A}$ previous study reported that the error rate of the diagnosis of C-spine injury in children aged $<8$ years was $24 \%$, and the most common factors associated with the misdiagnosis were the unfamiliarity with pediatric C-spine anatomy, the normal variants during growth and development, and the suboptimal conventional film techniques. ${ }^{14}$

The surgical management of C-spine instability accompanied by spinal cord compression can be implemented via either the anterior or the posterior approach. The posterior approach is carried out by laminectomy accompanied by insertion of titaniumbased screws to the vertebral pedicles and rods. The

Figure 4. X-ray 10 months after removing the cervical plate shows fusion of $\mathrm{C} 3, \mathrm{C} 4$, and $\mathrm{C} 5$ and improvement of the cervical curvature

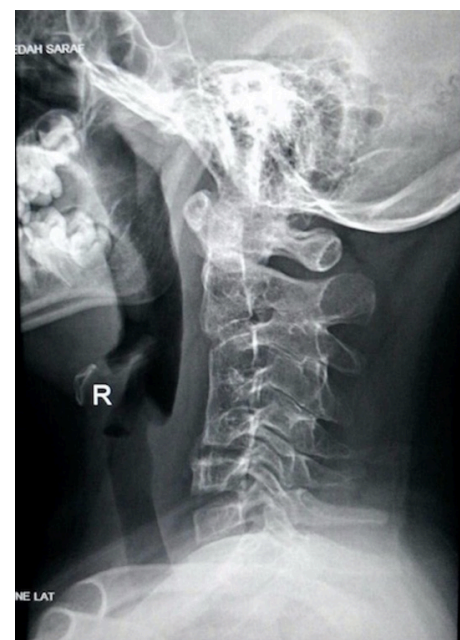

anterior approach is done by corpectomy, evacuation or removing the pressing material, reconstruction of the vertebral body after decompressing the spinal cord by titanium-based grafts or autograft from the iliac bone, and insertion of a titanium-based cervical plate. In this case, the anterior approach appeared to be superior due to several factors, i.e., directly find material that presses the spinal cord, and uses fewer implants. Using the autograft from the iliac bone and by removing the titanium-based cervical plate after 2 years at the age of 9 years, we were able to reduce the potential risk of instrumentation. Moreover, the second surgery for removing the titanium-based cervical plate was not a major one. IBG was preferred to use as it has been considered as the gold standard, ${ }^{15}$ and, moreover, a dedicated titanium-based graft for children is not yet available. The posterior approach would require the use of more implants and few physiological surgical procedures related to the removal of some vertebral laminae, and the pressing material itself was located in the anterior of the spinal cord. Removing the screws from the vertebral pedicles is also associated with difficulties, and the risk of the instability will return. Moreover, maintaining the implants has the risk of postsurgical deformity associated with the implants, inhibiting the growth potential of the C-spine in the fixed vertebral level. ${ }^{6,7}$

Deciding to remove or retain an implant after a successful stabilization and/or fusion is a difficult option. ${ }^{16}$ Lidar et al $^{17}$ reported an ACCF with plating by an absorbable cervical plate in a 2-year-old child. ${ }^{17}$ However, an absorbable cervical plate was not available 
in the hospital (Indonesia). Özer et $\mathrm{al}^{18}$ reported about temporary anterior cervical plating in a 7 -year-old child for an indication of traumatic cervical instability. Another previous study reported that the time to fusion ranged from 3 to 9 months..$^{19}$ Instead of removing the plate at 1 year after the first (primary) surgery, ${ }^{18}$ the authors removed the plate at 2 years after the first surgery (at the age of 9 years) to ensure that the fusion had occurred and the C-spine could continue its growth. It is believed that by the time a child reaches $8-10$ years of age, the cervical spine reaches adult proportions. ${ }^{20}$ However, a morphometric study reported that the normal vertical growth of the pediatric C-spine continues up to 18 years of age in boys. ${ }^{21}$

In the present case, 6 months after removing the cervical plate, the lateral $\mathrm{X}$-rays demonstrated an improvement of the cervical curvature (Figure 4; Table 1). In addition, there were no further clinical complaints. A previous study in adults stated that changes in the cervical spine sagittal alignment after neck injury should be considered as coincidental and not indicative of muscle spasms or osteoligamentous injury. ${ }^{22}$ Moreover, the absence of cervical spine lordosis can be observed in children up to the age of 16 years. ${ }^{20}$

\section{Conclusions}

Neck pain that is primarily worsening and/or triggered by movement of the neck or head is a significant symptom of C-spine instability after injury, as well as a compelling reason to perform radiographic examination. ACCF with iliac crest bone graft and plating, followed by removing the plate after 20 months, is a safe procedure and an effective treatment option for traumatic cervical instability accompanied by spinal cord compression in children.

\section{Conflict of Interest}

The authors affirm no conflict of interest in this study.

\section{Acknowledgment}

The authors would like to thank Prof. Ch B Lumenta, MD., Ph.D, and all staff members of the Department of Neurosurgery, Faculty of Medicine, Universitas Indonesia, Cipto Mangunkusumo Hospital for the valuable discussion and advice concerning the surgical management of the present case.

\section{Funding Sources}

None.

\section{REFERENCES}

1. Özgen S, Naderi S, Özek MM, Pamir MN. A retrospective review of cervical corpectomy: indications, complications and outcome. Acta Neurochir. 2004;146(10):1099-105.

2. Girard V, Leroux B, Brun V, Bressy G, Sesmat H, Madi K. Posttraumatic lower cervical spine instability: arthrodesis clinical and radiological outcomes at 5 years. Orthop Traumatol Surg Res. 2014;100(4):385-8.

3. Baron EM, Loftus CM, Vaccaro AR, Dominique DA. Anterior approach to the subaxial cervical spine in children: a brief review. Neurosurg Focus. 2006;20(2):E4.

4. Crostelli M, Mariani M, Mazza O, Ascani E. Cervical fixation in the pediatric patient: our experience. Eur Spine J. 2009;18:20-8.

5. Lastikka M, Aarnio J, Helenius I. Instrumented cervical spinal fusions in children: indication and outcomes. J Child Orthop. 2017;11(6):419-27.

6. Mortazavi M, Gore PA, Chang S, Tubbs RS, Theodore N. Pediatric cervical spine injuries: a comprehensive review. Childs Nerv Syst. 2011;27(5):705-17.

7. Upasani VV, Hedequist DJ, Hresko MT, Karlin LI, Emans JB, Glotzbecker MP. Spinal deformity progression after posterior segmental instrumentation and fusion for idiopathic scoliosis. J Child Orthop. 2015;9(1):29-37.

8. Savino F, Vagliano L, Ceratto S, Viviani F, Miniero R, Ricceri F. Pain assessment in children undergoing venipuncture: the Wong-Baker faces scale versus skin conductance fluctuations. PeerJ. 2013;1:e37.

9. Patel JC, Tepas JJ III, Mollitt DL, Pieper P. Pediatric cervical spine injuries: defining the disease. J Ped Surg. 2001;36(2):373-6.

10. Falavigna A, Righesso O, da Silva PG, Sanchez Chavez FA, Sfreddo E, Pelegrini de Almeida L, et al. Epidemiology and management of spinal trauma in children and adolescents $<18$ years old. World Neurosurg. 2018;110:e479-83.

11. Hoffman JR, Mower WR, Wolfson AB, Todd KH, Zucker MI, National X-Radiography Utilization Study group. Validity of a set of clinical criteria to rule out injury to the cervical spine in patients with blunt trauma. N Engl J Med. 2000;343(2):94-9.

12. Olson KA, Joder D. Diagnosis and treatment of cervical spine clinical instability. J Orthop Sports Phys Ther. 2001;31(4):194-206.

13. Hall DE, Boydston W. Pediatric neck injuries. Pediatr Rev. 1999;20(1):13-9.

14. Avellino AM, Mann FA, Grady MS, Chapman JR, Ellenbogen RG, Alden TD, et al. The misdiagnosis of acute cervical spine injuries and fractures in infants and children: the 12-year experience of a level I pediatric and adult trauma center. Childs Nerv Syst. 2005;21(2):122-7.

15. Vaz K, Verma K, Protpsaltis T, Schwab F, Lonner B, Errico T. Bone grafting options for lumbal spine surgery: a review examining clinical efficacy and complication. SAS J. 2010;4(3):75-86.

16. Dunn RN, Botha $A H$. Instrumentation of the paediatric cervical spine. SA Orthop J. 2014;13(1):44-9.

17. Lidar Z, Constantini S, Regev GJ, Salame K. Absorbable anterior cervical plate for corpectomy and fusion in a 2-year-old child with neurofibromatosis. J Neurosurg Pediatr. 2012;9(4):442-6.

18. Özer E, Yücesoy K, Kalemci O. Temporary anterior cervical plating in a child with traumatic cervical ligamentous instability. Pediatr Neurosurg. 2005;41(5):269-71.

19. Elder BD, Ishida W, Goodwin CC, Bydon A, Gokaslan ZL, Sciubba $D M$, et al. Bone graft option for spinal fusion following resection of spinal column tumors: systematic review and meta-analysis. Neurosurg Focus. 2017;42(1):E16.

20. Lustrin ES, Karakas SP, Ortiz AO, Cinnamon J, Castillo M, Vaheesan K, et al. Pediatric cervical spine: normal anatomy, variants, and trauma. Radiographics. 2003;23(3):539-60.

21. Johnson KT, Al-Holou WN, Anderson RC, Wilson TJ, Karnati $\mathrm{T}$, Ibrahim $\mathrm{M}$, et al. Morphometric analysis of the developing pediatric cervical spine. J Neurosurg Pediatr. 2016;18(3):377-89.

22. Beltsios M, Savvidou O, Mitsiokapa EA, Mavrogenis AF, Kaspiris A, Efstathopoulos $\mathrm{N}$, et al. Sagittal alignment of the cervical spine after neck injury. Eur J Orthop Surg Traumatol. 2013:23(Suppl 1):S47-51. 